\title{
Experimental and Four-Component Relativistic DFT Studies of Tungsten Carbonyl Complexes
}

\author{
Taye B. Demissie, ${ }^{1}$ Nataliya Kostenko, ${ }^{2}$ Stanislav Komorovsky, ${ }^{1}$ Michal Repisky, ${ }^{1}$ Johan \\ Isaksson, ${ }^{2, *}$ Annette Bayer, ${ }^{2, *}$ and Kenneth Ruud ${ }^{1, *}$ \\ ${ }^{1}$ Centre for Theoretical and Computational Chemistry, Department of Chemistry, University of \\ Tromsø - The Arctic University of Norway, N-9037 Tromsø, Norway \\ ${ }^{2}$ Department of Chemistry, University of Tromsø - The Arctic University of Norway, N-9037
}

Tromsø, Norway

\begin{abstract}
We present a theoretical and experimental study of the structure and NMR parameters of the pentacarbonyltungsten complexes of $\eta^{1}$-2-(trimethylstannyl)-4,5-dimethylphosphinine, $\eta^{2}$ norbornene and imidazolidine-2-thione. The three complexes have a pseudo-octahedral molecular structure with the six ligands bonded to the tungsten atom. The $\eta^{1}-2$ (trimethylstannyl)-4,5-dimethylphosphinine-pentacarbonyl complex was synthesized for the first time. For all compounds we present four-component relativistic calculations of the nuclear magnetic resonance (NMR) parameters at the Dirac-Kohn-Sham density functional level of theory using hybrid functionals. These large-scale relativistic calculations of NMR chemical shifts and spin-spin coupling constants were compared to available experimental data, either taken from the literature or measured in this work. The inclusion of solvent effects modeled using a conductor-like screening model (COSMO) was found to improve agreement between the calculated and experimental NMR parameters, and our best estimates for the NMR parameters are generally in good agreement with available experimental results. The present work demonstrates that four-component relativistic theory has reached a level of maturity that makes it a convenient and accurate tool for modeling and understanding chemical shifts and indirect spinspin coupling constants of organometallic compounds containing heavy elements, for which conventional non-relativistic theory breaks down.
\end{abstract}

Keywords: tungsten carbonyl; heavy elements; NMR; spin-spin coupling constants; fourcomponent calculations; relativistic effects 


\section{INTRODUCTION}

Transition metal complexes are of great interest due to their numerous applications in catalysis. For instance, tungsten oxide catalysts have widespread use in industry for catalyzing reactions such as metathesis, hydrodesulphurization, alcohol synthesis, acid synthesis and hydrodenitrogenation. ${ }^{[1-4]}$ Tungsten hexacarbonyl and its derivatives have also been used as photochromic substances and as efficient and reusable catalysts for epoxidation of alkenes with hydrogen peroxide. ${ }^{[5]}$ The investigation of transition metal complexes and their properties can thus aid researchers in the industrialization of catalytic processes, chemisorption and organic chemistry as well as fundamental aspects of biochemistry. ${ }^{[1,6-8]}$ A number of studies have also shown that transition metal systems are efficient in activating carbon-oxygen bonds. This could help in designing efficient metal complexes that can be used to reduce the oxides of carbon, the major causes of global warming due to human activities. Therefore, an understanding of the physico-chemical properties of metal complexes is of great importance.

Nuclear magnetic resonance (NMR) is a powerful tool for elucidating molecular structure and to provide insight into the electronic structure of a molecule. However, the presence of heavy atoms near the light atoms of the ligands affects the NMR properties of the ligand atoms, the so-called heavy-atom effects on light atoms (HALA effect), ${ }^{[9-10]}$ making the interpretation of the spectra difficult and requiring that relativistic effects are included in the calculations. ${ }^{[11-19]}$ Among the most important relativistic Hamiltonians which are used to study NMR parameters and include relativistic corrections variationally are the two-component zeroth-order-regularapproximation (ZORA) Hamiltonian ${ }^{[20]}$ and the four-component Dirac-Coulomb Hamiltonian, in both cases in combination with density-functional theory (DFT).

Four-component relativistic calculations hold great promise for the study of NMR properties of organometallic complexes. However, until recently the use of relativistic four-component methods for the study of NMR properties of transition-metal complexes were limited to rather small systems. We have recently demonstrated the maturity of four-component relativistic calculations at the DFT level using the ReSpect code, ${ }^{[21]}$ showing that fast and reliable determination of NMR properties of relatively large organic systems containing bromine and iodine atoms is now possible. ${ }^{[15,22]} \mathrm{We}$ have also presented studies of the $\mathrm{NMR}^{[23]}$ and electron paramagnetic resonance $(\mathrm{EPR})^{[24]}$ properties of paramagnetic transition metal complexes. 
In this work we apply the four-component methodology ${ }^{[25-27]}$ to the calculation of both NMR chemical shifts and indirect spin-spin coupling constants of large systems containing transition metal elements. In particular, we present the first applications of the ReSpect code to the calculation of NMR parameters using hybrid functionals, showing that the inclusion of exact exchange is important in many cases in order to reliably predict NMR properties of organometallic complexes. As a demonstration, we aimed to study three tungsten carbonyl complexes, each with six ligands attached to the metal center by carbon, phosphorus and sulfur atoms. This set of molecules also contains a newly synthesized ( $\eta^{1}-2$-(trimethylstannyl)-4,5dimethylphosphinine)-pentacarbonyltungsten (1) complex, and its synthesis and NMR parameters are also reported here. The latter compound contains two heavy metal atoms, tungsten and tin, making it an interesting candidate for relativistic NMR property calculations. The synthesis and experimental NMR parameters of the remaining two molecules, $\eta^{2}$ norbornene-pentacarbonyltungsten (2) and imidazolidine-2-thione-pentacarbonyltungsten (3), have been reported previously by Górski et al., ${ }^{[28]}$ and Merniz et al., ${ }^{[29]}$ respectively. The structures of all molecules together with their atom numbering are shown in Figure 1.

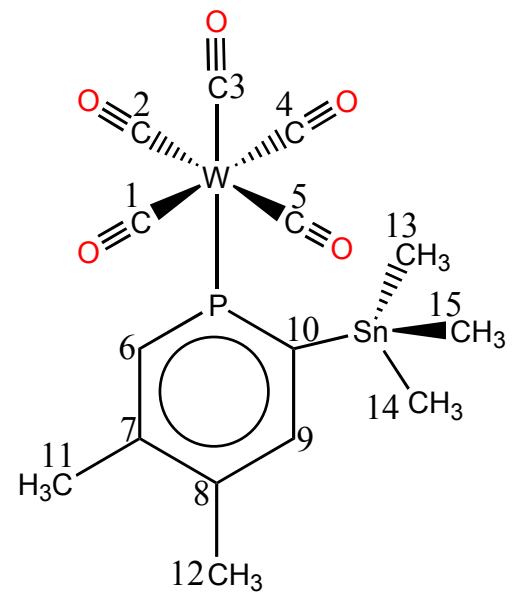

1

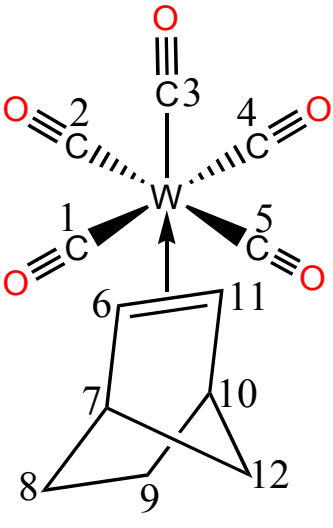

2

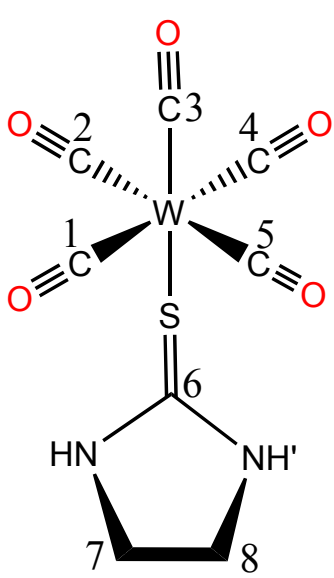

3

Figure 1. Structures of the tungsten carbonyl complexes $\mathbf{1}-\mathbf{3}$ with the atom numbering used throughout the text.

\section{EXPERIMENTAL DETAILS}

\section{General Remarks}


All oxygen and/or water sensitive reactions were carried out under dry nitrogen using Schlenk techniques with oven-dried glassware and dry solvents. Tetrahydrofuran (THF) and pentane were distilled under dry nitrogen from sodium/benzophenone and methylene chloride from $\mathrm{P}_{2} \mathrm{O}_{5}$ before use. Solution of $1.8 \mathrm{M}$ phenyllithium in di-n-butyl ether, hexacarbonyl tungsten and trimethyltin chloride were purchased from Sigma Aldrich. The 2-bromo-4,5dimetylphosphinine was prepared according to the literature method. ${ }^{[30]}$ Silica gel (Davisil

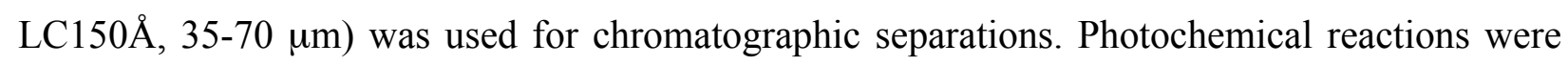
performed using a mercury-quartz lamp and a quartz Schlenk vessel fitted with a water jacket. NMR spectra were recorded on a Varian (now Agilent) Mercury Plus spectrometer operating at 399.971 MHz $\left({ }^{1} \mathrm{H}\right), 100.583 \mathrm{MHz}\left({ }^{13} \mathrm{C}\right), 161.935 \mathrm{MHz}\left({ }^{31} \mathrm{P}\right)$ and $149.163 \mathrm{MHz}\left({ }^{119} \mathrm{Sn}\right)$, equipped with a room-temperature indirect ${ }^{1} \mathrm{H} /{ }^{19} \mathrm{~F}$ double-tuned broadband probe (ATB, ${ }^{1} \mathrm{H} /{ }^{19} \mathrm{~F},\left[{ }^{15} \mathrm{~N}-{ }^{31} \mathrm{P}\right]$ ). The scalar coupling constants $(J)$ are given in $\mathrm{Hz}$ and are either measured by deconvolution of directly observed $1 \mathrm{D}$ spectra, or from X-nuclei induced E-cosy type patterns in $2 \mathrm{D}{ }^{1} \mathrm{H},{ }^{13} \mathrm{C}$ HSQC, ${ }^{1} \mathrm{H},{ }^{13} \mathrm{C}-\mathrm{HMBC}$ and DQF-COSY experiments. ${ }^{1} \mathrm{H}$ and ${ }^{13} \mathrm{C}$ chemical shifts $(\delta)$ are reported in ppm relative to the residual peak of chloroform, $\delta_{\mathrm{H}}=7.26 \mathrm{ppm}, \delta_{\mathrm{C}}=77.16 \mathrm{ppm} .{ }^{1} \mathrm{H}$ and ${ }^{13} \mathrm{C}$ chemical shifts were assigned by 2D NMR experiments (H,H-COSY, HSQC and HMBC). ${ }^{31} \mathrm{P}$ NMR spectra were recorded using an insertion NMR tube filled with $\mathrm{PPh}_{3}$ in $\mathrm{C}_{6} \mathrm{D}_{6}(\delta=-5.4$ $\mathrm{ppm})$ as a reference. The ${ }^{119} \mathrm{Sn}$ NMR spectrum was recorded using an insertion NMR tube filled with trimethyltin chloride in $\mathrm{CDCl}_{3}(\delta=171.6 \mathrm{ppm})$ as a reference. Signal patterns are indicated as s (singlet), $\mathrm{d}$ (doublet) and dd (doublet of doublet). All directly observed X-nuclei experiments were acquired with waltz16 proton decoupling at $15.9 \mathrm{kHz}$ during the pulse sequence and acquisition. High-resolution mass spectra (HRMS) were recorded on a LTQ Orbitrap XL (Thermo Scientific) in positive electrospray ionization (ESI) mode.

\section{( $\eta^{1}$-2-Bromo-4,5-dimethylphosphinine)-pentacarbonyltungsten (1a)}

A solution of $\mathrm{W}(\mathrm{CO})_{5} \bullet \mathrm{THF}$ was prepared by $\mathrm{UV}$ irradiation $\left(3.5 \mathrm{hrs}, 4^{\circ} \mathrm{C}\right)$ of $\mathrm{W}(\mathrm{CO})_{6}(5.53$ $\mathrm{g}, 0.016 \mathrm{~mol})$ in THF $(150 \mathrm{ml})$. Then 2-bromo-4,5-dimethylphosphinine $(3.1 \mathrm{~g}, 0.015 \mathrm{~mol})$ in THF $(100 \mathrm{ml})$ was added to the $\mathrm{W}(\mathrm{CO})_{5} \bullet \mathrm{THF}$ solution at room temperature while stirring. The mixture was stirred at room temperature for $0.5 \mathrm{~h}$ and then heated at $40^{\circ} \mathrm{C}$ for another $2 \mathrm{hrs}$. The reaction mixture turned from yellow to green-yellow. The volatiles were removed in vacuo. The 
residue was dissolved in methylene chloride $(100 \mathrm{ml})$ and insolubles were filtered off. The filtrated solution was chromatographed on silica with pentane to give a yellow crystalline solid.

Characterization of $1 \mathbf{a}$ : yellow; solid; $4.51 \mathrm{~g} ; 56 \% ;{ }^{1} \mathrm{H} \mathrm{NMR}\left(\mathrm{CDCl}_{3}\right): \delta=2.33\left(\mathrm{~d},{ }^{5} J(\mathrm{P}-\mathrm{H})=\right.$ 6.4, 4- $\left.\mathrm{CH}_{3}, 3 \mathrm{H}\right), 2.35\left(\mathrm{~d},{ }^{4} J(\mathrm{P}-\mathrm{H})=1.8,5-\mathrm{CH}_{3}, 3 \mathrm{H}\right), 8.03\left(\mathrm{~d},{ }^{2} J(\mathrm{P}-\mathrm{H})=25.9,6-\mathrm{H}, 1 \mathrm{H}\right), 8.04(\mathrm{~d}$, $\left.{ }^{3} J(\mathrm{P}-\mathrm{H})=14.4,3-\mathrm{H}, 1 \mathrm{H}\right) ;{ }^{13} \mathrm{C} \mathrm{NMR}\left(\mathrm{CDCl}_{3}\right): \delta=22.1\left(\mathrm{~d},{ }^{4} J(\mathrm{P}-\mathrm{C})=4.1,4-\mathrm{CH}_{3}\right), 23.2\left(\mathrm{~d},{ }^{3} J(\mathrm{P}-\mathrm{C})\right.$ $\left.=9.9,5-\mathrm{CH}_{3}\right), 139.0\left(\mathrm{~d},{ }^{3} J(\mathrm{P}-\mathrm{C})=24.3, \mathrm{C}-4\right), 142.7\left(\mathrm{~d},{ }^{2} J(\mathrm{P}-\mathrm{C})=10.8 . \mathrm{C}-5\right), 144.2\left(\mathrm{~d},{ }^{1} J(\mathrm{P}-\mathrm{C})=\right.$ 16.9, C-2), $146.4\left(\mathrm{~d},{ }^{2} J(\mathrm{P}-\mathrm{C})=17.3, \mathrm{C}-5\right), 151.8\left(\mathrm{~d},{ }^{1} J(\mathrm{P}-\mathrm{C})=17.3, \mathrm{C}-6\right), 194.1[(\mathrm{~d}, J=9.4),(\mathrm{dd}$, $\left.{ }^{1} J(\mathrm{P}-\mathrm{C})=125.1,9.3\right)$, cis-CO], $198.4\left(\mathrm{~d},{ }^{1} J(\mathrm{P}-\mathrm{C})=32.7\right.$, trans-CO $) ;{ }^{31} \mathrm{P}$ NMR $\left(\mathrm{C}_{6} \mathrm{D}_{6}\right): \delta=167.9$ $\left[(\mathrm{s}),\left(\mathrm{d},{ }^{1} J(\mathrm{P}-\mathrm{W})=279.1\right)\right]$; HRMS: Calculated for $(\mathrm{M}+\mathrm{H})^{+} \mathrm{C}_{13} \mathrm{H}_{8} \mathrm{O}_{5} \mathrm{BrPWH}, 526.8877$ found 526.8864 .

\section{( $\eta^{\mathbf{1}}$-2-(Trimethylstannyl)-4,5-dimethylphosphinine)-pentacarbonyltungsten (1)}

To a solution of $1 \mathrm{a}(0.66 \mathrm{~g}, 1.26 \mathrm{mmol})$ in THF $(11 \mathrm{ml})$ at $-80^{\circ} \mathrm{C}$, a $1.8 \mathrm{M}$ phenyl lithium solution in dibutyl ether $(0.70 \mathrm{ml}, 1 \mathrm{eq})$ was added dropwise while stirring. The reaction mixture was stirred at $-80^{\circ} \mathrm{C}$ for $5 \mathrm{~min}$ and trimethyltin chloride $(0.26 \mathrm{~g}, 1.29 \mathrm{mmol})$ in THF $(1.5 \mathrm{ml})$ was added. The reaction mixture was further stirred at $-80^{\circ} \mathrm{C}$ for $0.5 \mathrm{~h}$ and overnight at room temperature. Then, volatiles were removed in vacuo and the dark-brown oily residue was extracted with pentane $(40 \mathrm{ml})$. The obtained extract was filtered through a Celite pad and then chromatographed on silica with pentane. The product $(0.49 \mathrm{~g}, 64 \%)$ elutes as first fraction and is a pale-yellow crystalline solid sensitive to moisture. The synthesis is shown in Scheme 1.

Characterization of 1: pale yellow; solid; $0.49 \mathrm{~g} ; 64 \% ;{ }^{1} \mathrm{H} \mathrm{NMR}\left(\mathrm{CDCl}_{3}\right): \delta=0.48\left[\left(\mathrm{~s},{ }^{\text {inactive }} \mathrm{Sn}-\right.\right.$ $\left.\left.\mathrm{CH}_{3}\right),\left(\mathrm{d},{ }^{2} J\left({ }^{119} \mathrm{Sn}-\mathrm{H}\right)=56.7,{ }^{119} \mathrm{Sn}-\mathrm{CH}_{3}\right),\left(\mathrm{d},{ }^{2} J\left({ }^{117} \mathrm{Sn}-\mathrm{H}\right)=53.0,{ }^{117} \mathrm{Sn}-\mathrm{CH}\right), 9 \mathrm{H}\right], 2.36\left(\mathrm{~d},{ }^{5} J(\mathrm{P}-\right.$ $\mathrm{H})=6.2,12-\mathrm{H}, 3 \mathrm{H}), 2.40\left(\mathrm{~d},{ }^{4} J(\mathrm{P}-\mathrm{H})=1.6,11-\mathrm{H}, 3 \mathrm{H}\right), 7.86\left[\left(\mathrm{~d},{ }^{3} J(\mathrm{P}-\mathrm{H})=30.7\right),\left(\mathrm{dd},{ }^{3} J\left({ }^{119} \mathrm{Sn}-\right.\right.\right.$ $\left.\left.\mathrm{H})=61.4,{ }^{3} J(\mathrm{P}-\mathrm{H})=30.7\right),\left(\mathrm{dd},{ }^{3} J\left({ }^{117} \mathrm{Sn}-\mathrm{H}\right)=60.7,{ }^{3} J(\mathrm{P}-\mathrm{H})=30.7\right), 9-\mathrm{H}, 1 \mathrm{H}\right], 8.26\left[\left(\mathrm{~d},{ }^{2} J(\mathrm{P}-\mathrm{H})\right.\right.$ $\left.=23.3),\left(\mathrm{d},{ }^{2} J(\mathrm{P}-\mathrm{H})=23.6,{ }^{4} J(\mathrm{Sn}-\mathrm{H})=20.1\right), 6-\mathrm{H}, 1 \mathrm{H}\right] ;{ }^{13} \mathrm{C} \mathrm{NMR}\left(\mathrm{CDCl}_{3}\right): \delta=-6.7\left[\left(\mathrm{~d},{ }^{3} J(\mathrm{P}-\mathrm{C})\right.\right.$ $=2.5),\left(\mathrm{dd},{ }^{1} J\left({ }^{119} \mathrm{Sn}-\mathrm{C}\right)=360.7,{ }^{3} J(\mathrm{P}-\mathrm{C})=2.5\right),\left(\mathrm{dd},{ }^{1} J\left({ }^{117} \mathrm{Sn}-\mathrm{C}\right)=345.1,{ }^{3} J(\mathrm{P}-\mathrm{C})=2.5\right), \mathrm{Sn}-$ $\left.\left.C_{3}\right)\right], 22.3\left(\mathrm{~d},{ }^{4} J(\mathrm{P}-\mathrm{C})=4.1, \mathrm{C}-12\right), 23.5\left[\left(\mathrm{~d},{ }^{3} J(\mathrm{P}-\mathrm{C})=8.1\right),\left(\mathrm{dd},{ }^{3} J(\mathrm{P}-\mathrm{C})=8.1,{ }^{5} J(\mathrm{Sn}-\mathrm{C})=5.3\right)\right.$, $\mathrm{C}-11], 136.0\left[\left(\mathrm{~d},{ }^{3} J(\mathrm{P}-\mathrm{C})=36.8\right),\left(\mathrm{dd},{ }^{3} J(\mathrm{P}-\mathrm{C})=36.8,{ }^{3} J(\mathrm{Sn}-\mathrm{C})=19.9\right), \mathrm{C}-8\right], 146.8\left[\left(\mathrm{~d},{ }^{2} J(\mathrm{P}-\right.\right.$ $\left.\mathrm{C})=21.2),\left(\mathrm{dd},{ }^{2} J(\mathrm{P}-\mathrm{C})=21.1,{ }^{3} J(\mathrm{Sn}-\mathrm{C})=10.9\right), \mathrm{C}-9\right], 147.6\left[\left(\mathrm{~d},{ }^{2} J(\mathrm{P}-\mathrm{C})=15.8\right),\left(\mathrm{dd},{ }^{2} J(\mathrm{P}-\mathrm{C})=\right.\right.$ $15.8], 153.7\left[\left(\mathrm{~d},{ }^{1} J(\mathrm{P}-\mathrm{C})=9.5\right),\left(\mathrm{dd},{ }^{1} J(\mathrm{P}-\mathrm{C})=9.5,{ }^{2} J(\mathrm{~W}-\mathrm{C})=5.9\right),\left(\mathrm{dd},{ }^{1} J(\mathrm{P}-\mathrm{C})=9.5,{ }^{3} J(\mathrm{Sn}-\mathrm{C})\right.\right.$ $=33.7), \mathrm{C}-6], 163.8\left[\left(\mathrm{~d},{ }^{1} J(\mathrm{P}-\mathrm{C})=26.9\right),\left(\mathrm{dd},{ }^{1} J(\mathrm{P}-\mathrm{C})=26.9,{ }^{2} J(\mathrm{~W}-\mathrm{C})=6.9\right),\left(\mathrm{dd},{ }^{1} J\left({ }^{119} \mathrm{Sn}-\mathrm{C}\right)=\right.\right.$ 
340.6, $\left.\left.{ }^{1} J(\mathrm{P}-\mathrm{C})=26.6\right),\left(\mathrm{dd},{ }^{1} J\left({ }^{117} \mathrm{Sn}-\mathrm{C}\right)=324.8,{ }^{1} J(\mathrm{P}-\mathrm{C})=26.9\right), \mathrm{C}-10\right], 195.8\left[\left(\mathrm{~d},{ }^{2} J(\mathrm{P}-\mathrm{C})=\right.\right.$ 9.2), (dd, $\left.\left.{ }^{2} J(\mathrm{P}-\mathrm{C})=9.3,{ }^{1} J(\mathrm{~W}-\mathrm{C})=125.9\right), c i s-\mathrm{CO}\right], 198.9\left[\left(\mathrm{~d},{ }^{2} J(\mathrm{P}-\mathrm{C})=28.0\right),\left(\mathrm{dd},{ }^{2} J(\mathrm{P}-\mathrm{C})=\right.\right.$ 28.0, $\left.{ }^{1} J(\mathrm{~W}-\mathrm{C})=147.4\right)$, trans-CO]; ${ }^{31} \mathrm{P}$ NMR $\left(\mathrm{C}_{6} \mathrm{D}_{6}\right): \delta=174.7\left[(\mathrm{~s}),\left(\mathrm{d},{ }^{1} J(\mathrm{P}-\mathrm{W})=259.6\right),(\mathrm{d}\right.$, $\left.\left.{ }^{2} J\left({ }^{119} \mathrm{Sn}-\mathrm{P}\right)=193.7\right),\left(\mathrm{d},{ }^{2} J\left({ }^{117} \mathrm{Sn}-\mathrm{P}\right)=184.4\right)\right] ;{ }^{119} \mathrm{Sn} \mathrm{NMR}\left(\mathrm{CDCl}_{3}\right): \delta=-1.44\left(\mathrm{~d},{ }^{2} J(\mathrm{Sn}-\mathrm{P})=\right.$ 193.7).

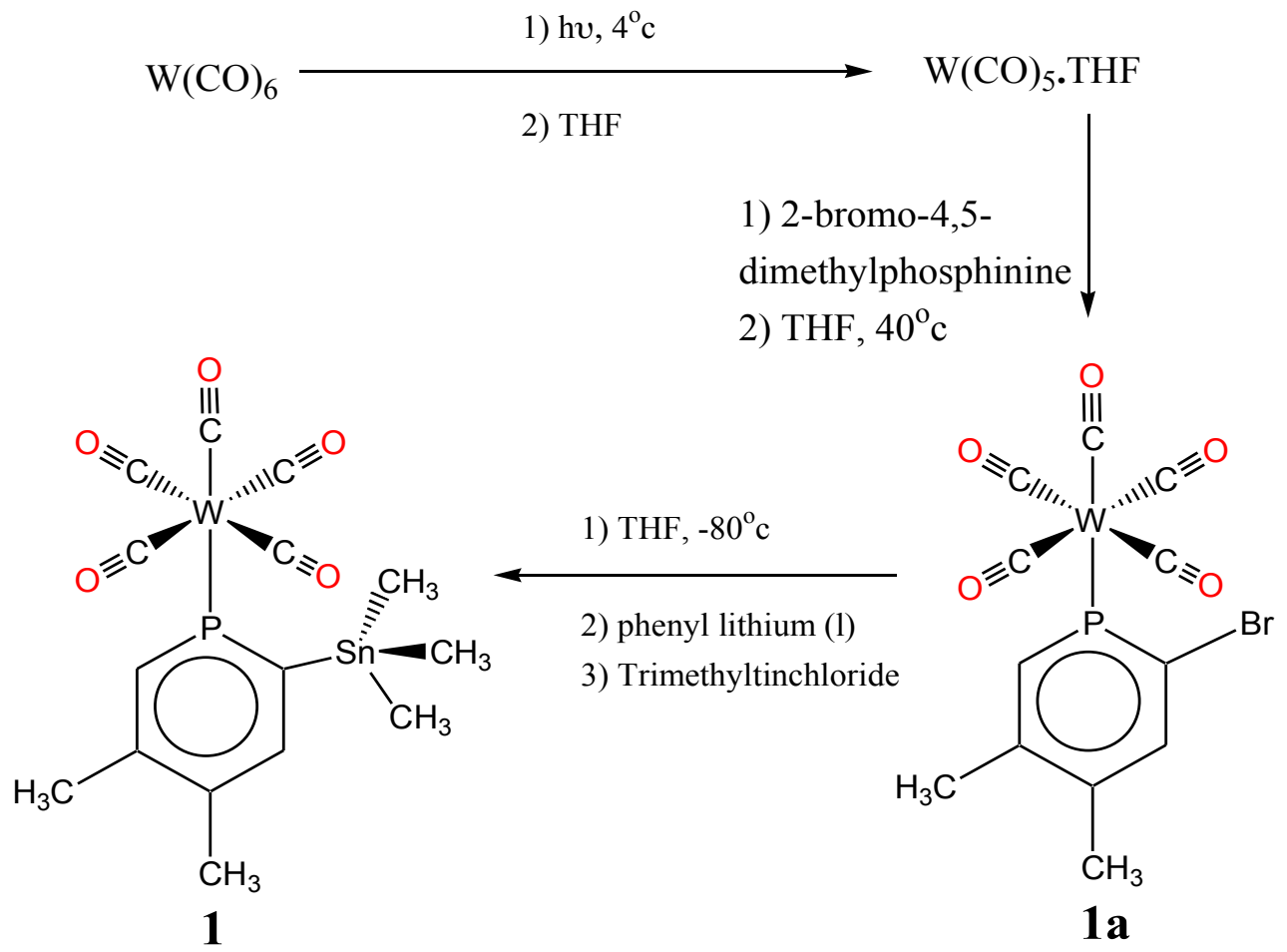

Scheme 1. Synthesis of 1

\section{COMPUTATIONAL DETAILS}

The $\mathrm{BP} 86^{[31-32]}$ and B3LYP ${ }^{[33-36]}$ functionals together with the ZORA-optimized TZ2 $\mathrm{P}^{[37]}$ basis set were used for the geometry optimizations in delocalized coordinates with the 2014 version of the Amsterdam density functional $(\mathrm{ADF})^{[38]}$ program package employing the spinorbit ZORA (SO-ZORA). ${ }^{[20,39-40]}$ For all optimized structures, a frequency calculation was performed to verify that the structures correspond to true minima and thus do not display imaginary frequencies. Grimme's dispersion correction $^{[41]}$ was used with both functionals (abbreviated as BP86-D3 and B3LYP-D3) in ADF. The four-component relativistic NMR property calculations were performed using the ReSpect electronic structure program package ${ }^{[21]}$ 
that employs the restricted magnetic balance concept to ensure fast basis set convergence ${ }^{[25-26]}$ and gauge-including atomic orbitals (GIAO) to ensure gauge-origin independent results. ${ }^{\text {[27] }}$

Helgaker et al. ${ }^{[42]}$ showed that spin-spin coupling constants obtained at the local density approximation (LDA) and generalized gradient approximation (GGA) levels are poorer than those obtained at the B3LYP level, with errors often several times larger. Hence, for the spinspin coupling constant calculations, we used the B3LYP ${ }^{[33-36]}$ and $\mathrm{BP} 86^{[31-32]}$ functionals (the latter for comparison) together with the uncontracted pcJ-2 (triple- $\zeta$ quality) basis sets ${ }^{[43]}$ for the light atoms and the uncontracted Dyall's relativistic valence triple- $\zeta$ (denoted as dyall-vtz) basis sets for $\operatorname{tin}^{[44]}$ and tungsten. ${ }^{[45-46]}$ In our previous study, ${ }^{[22]}$ we showed that GGA functionals give reliable results for chemical shifts of compounds containing heavy elements, allowing highaccuracy results to be obtained using the advanced relativistic implementations. Therefore, in all the four-component chemical shift calculations, the BP86 functional together with the same triple- $\zeta$ quality basis sets as used for the calculations of the spin-spin coupling constants were used.

For determining the chemical shifts, the calculated ${ }^{1} \mathrm{H}$ and ${ }^{13} \mathrm{C}$ shielding constants of tetramethylsilane (TMS) were used as reference for the proton and carbon chemical shifts. For the chemical shift calculation of phosphorus, triphenylphosphine $\left(\mathrm{PPh}_{3}\right)$ was used as reference, whereas tetramethyltin (TMT) was used as reference for the chemical shift determination of tin in 1. For the tungsten chemical shift calculations, the chemical shielding of tungsten in the tetroxotungstate anion $\left(\mathrm{WO}_{4}{ }^{2-}\right)$ was used as a reference. The main focus of the four-component spin-spin coupling constants calculations is for coupling constants involving heavy atoms and with larger magnitude. However, for the sake of comparison, also a few other coupling constants are reported. All calculated spin-spin coupling constants values using SO-ZORA are presented in the supporting information. The solvent effects on the calculated chemical shifts of ${ }^{1} \mathrm{H}$ and ${ }^{13} \mathrm{C}$ as well as spin-spin couplings were determined from the calculations performed in gas-phase and in chloroform in a conductor-like screening model (COSMO) ${ }^{[47]}$ employing the SO-ZORA relativistic approach as implemented in ADF. 


\section{RESULTS AND DISCUSSION}

\subsection{Molecular Geometries}

Selected structural parameters of the three complexes are listed in Table 1. In 1, the optimized structural parameters show that there are no considerable changes in the C-C unsaturated bonds compared to those of standard aromatic hydrocarbons. The $\mathrm{C} 8 \mathrm{-C} 12$ and $\mathrm{C} 7-$

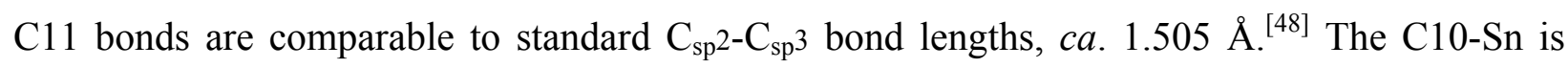
longer than C14-Sn as well as the Sn-C bond in TMT (2.184 $\AA$ ), even though the former carbon atom is $\mathrm{sp}^{2}$ hybridized. This is mainly due to steric crowding. The W-C6 and W-C11 bond lengths of $\mathbf{2}$ indicate that the norbornene is only weakly bonded to the tungsten atom. In $\mathbf{3}$, the C7-C8 bond length (exp. 1.536 $\AA$ ) is longer than the standard $\mathrm{C}_{\mathrm{sp}} 3-\mathrm{C}_{\mathrm{sp}} 3$ bond length. The sulfur atom of the thiol group is $\mathrm{sp}^{3}$ hybridized as is confirmed from the W-S-C6 bond angle of $109.5^{\circ}$ in the X-ray structure ${ }^{[29]}$ and $100.5^{\circ}$ in the optimized geometry.

In all three complexes, the $\mathrm{W}-\mathrm{C}(\mathrm{CO})$ bond lengths trans to the sixth ligand are shorter than the other equatorial $\mathrm{W}-\mathrm{C}(\mathrm{CO})$ bonds due to the trans influence of the carbonyl ligand, making the bond between tungsten and the sixth ligand labile (see Table 1). Such a difference in bond lengths has a noticeable effect on the NMR parameters (vide infra). The W-C(CO) bonds show only minor deviations from an undistorted octahedral arrangement. However, this minor distortion leads to small deviations in the linearity of the W-CO bonds, with the biggest deviation being observed in gas phase with $177.0^{\circ}$. Moreover, in all the three complexes, the adjacent W$\mathrm{C}(\mathrm{CO})$ bond vectors are nearly perpendicular, and those in the trans arrangement are nearly linear. The results also show that the ligands are fixed in a pseudo-octahedral arrangement around the tungsten atom. The overall analysis of the structural parameters shows that both functionals (BP86-D3 $3^{[31-32,41]}$ and B3LYP-D $3^{[33-36,41]}$ ) reproduce the structural parameters of the available X-ray data of $\mathbf{2}$ and $\mathbf{3}$ well. Considering the good agreement between theory and experiment for $\mathbf{2}$ and $\mathbf{3}$, we assume that the calculated structural parameters of $\mathbf{1}$ provide a good description of the geometry of the newly synthesized complex. 
Table 1. Selected bond lengths (in $\AA$ ) and angles (in degrees) of complexes $\mathbf{1}-\mathbf{3}$ obtained from BP86-D3 geometry optimizations together with available experimental values. ${ }^{\text {a }}$

\begin{tabular}{|l|c|c|c|c|c|c|c|c|}
\hline & \multicolumn{2}{|c|}{1} & \multicolumn{3}{c|}{$\mathbf{2}$} & \multicolumn{3}{c|}{3} \\
\cline { 2 - 10 } & Gas phase & $\mathrm{CHCl}_{3}$ & Gas phase & $\mathrm{CHCl}_{3}$ & Exp. $^{[28]}$ & Gas phase & $\mathrm{CHCl}_{3}$ & Exp. $^{[29}$ \\
\hline W-C1 & 2.045 & 2.043 & 2.051 & 2.046 & 2.049 & 2.041 & 2.035 & 2.050 \\
\hline W-C3 & 2.009 & 2.004 & 2.014 & 1.987 & 1.983 & 1.978 & 1.970 & 1.970 \\
\hline W-C5 & 2.046 & 2.043 & 2.047 & 2.040 & 2.071 & 2.042 & 2.040 & 2.055 \\
\hline W-C6 & - & - & 2.408 & 2.499 & 2.497 & - & - & - \\
\hline W-S & - & - & - & - & - & 2.625 & 2.613 & 2.599 \\
\hline W-P & 2.513 & 2.503 & - & - & - & - & - & - \\
\hline C6-C7 & 1.394 & 1.395 & 1.528 & 1.522 & 1.540 & - & - & - \\
\hline S-C6 & - & - & - & - & - & 1.709 & 1.727 & 1.711 \\
\hline C7-C8 & 1.417 & 1.419 & 1.571 & 1.571 & 1.560 & 1.559 & 1.545 & 1.536 \\
\hline C8-C9 & 1.404 & 1.404 & 1.565 & 1.564 & 1.530 & - & - & - \\
\hline C9-C10 & 1.405 & 1.405 & 1.570 & 1.571 & 1.560 & - & - & - \\
\hline C10-Sn & 2.195 & 2.191 & - & - & - & - & - & - \\
\hline C14-Sn ${ }^{b}$ & 2.176 & 2.173 & - & - & - & - & - & - \\
\hline C1-W-C2 & 89.0 & 88.9 & 91.2 & 91.7 & 91.8 & 92.4 & 89.8 & 92.6 \\
\hline C2-W-C5 & 177.0 & 178.8 & 172.3 & 172.6 & 173.4 & 177.4 & 178.8 & 176.8 \\
\hline C3-W-P & 173.0 & 175.5 & - & - & - & - & - & - \\
\hline C3-W-S & - & - & - & - & - & 175.3 & 177.4 & 172.4 \\
\hline C3-W-C5 & 87.5 & 89.7 & 86.9 & 86.0 & 86.3 & 89.6 & 90.6 & 89.7 \\
\hline C4-W-C5 & 89.9 & 91.6 & 88.7 & 88.3 & 90.8 & 88.7 & 90.4 & 88.4 \\
\hline
\end{tabular}

${ }^{\text {a }}$ Full optimized geometries using either BP86-D3 or B3LYP-D3 are presented in the Supplementary Information.

${ }^{\mathrm{b}}$ The optimized Sn-C bond length in TMT is $2.184 \AA$

\subsection{NMR Chemical Shifts}

The calculated and experimental proton chemical shifts for $\mathbf{1}-\mathbf{3}$ are listed in Table 2. The calculated average chemical shifts of the protons of the methyl group attached to the ring in $\mathbf{1}$ have chemical shifts of $2.40 \mathrm{ppm}$ and $2.44 \mathrm{ppm}$, respectively, for H11 and H12. They are shifted 
downfield compared to the protons of the methyl groups attached to tin, mainly due to aromatic ring-current effects. A comparison of the proton chemical shifts of H6 and H9 shows that the former is deshielded by phosphorous. The calculated chemical shift of H6 also shows that it is slightly more sensitive to the solvent than the other protons. The solvent-corrected proton chemical shifts are in fair agreement with the experimental values.

In 2, the chemical shifts of $\mathrm{H} 6$ and $\mathrm{H} 11$ are less than the olefinic protons of the uncomplexed norbornene $(5.95 \mathrm{ppm}),{ }^{[49]}$ showing an influence of tungsten on the proton chemical shifts. The proton attached to $\mathrm{C} 7$ of $\mathbf{2}$ is deshielded compared to the other protons on the $\mathrm{sp}^{3}$ hybridized carbon atoms due to the nearby $\pi$-electrons. H8a and H8b of the norbornene unit of $\mathbf{2}$ are deshielded compared to the corresponding protons of the uncomplexed norbornene (1.03 ppm and $1.32 \mathrm{ppm}$, respectively). ${ }^{[49]}$ Protons of $\mathbf{3}$ that are attached to carbon have chemical shifts very close to each other. However, those attached to the nitrogen atoms are slightly deshielded compared to the other protons due to the electronegativity of nitrogen. We note that for both $\mathbf{1}$ and $\mathbf{2}$, the inclusion of solvent effects improves the agreement between the calculated and experimental values. For this reason, we believe that the solvent and relativistically corrected proton chemical shifts of $\mathbf{3}$ provide reliable estimates for the $\delta\left({ }^{1} \mathrm{H}\right)$ for which no experimental observations have been reported. ${ }^{[29]}$

Table 2. Experimental and calculated (BP86) ${ }^{1} \mathrm{H}$ chemical shifts for complexes $\mathbf{1}$ - $\mathbf{3}$ (in ppm). The average of the calculated values are reported for the methyl protons of $\mathbf{1}$ to be consistent with experiment.

\begin{tabular}{|c|c|c|c|c|c|c|c|c|c|c|c|c|c|}
\hline \multicolumn{5}{|c|}{1} & \multicolumn{5}{|c|}{$2^{e}$} & \multicolumn{4}{|c|}{3} \\
\hline tom & $\delta^{\text {gas, a }}$ & $\Delta \delta^{\text {solv., b }}$ & $\delta^{\text {tot., c }}$ & $\delta^{\exp , d}$ & Atom & $\delta^{\mathrm{gas}, \mathrm{a}}$ & $\Delta \delta^{\text {solv.,b }}$ & $\delta^{\text {tot., c }}$ & $\delta^{\text {exp.[28] }}$ & Atom & $\delta^{\text {gas, a }}$ & $\Delta \delta^{\text {solv., b }}$ & $\delta^{\text {tot., c }}$ \\
\hline 6 & 8.88 & -0.39 & 8.49 & 8.26 & H6 & 4.80 & -0.01 & 4.79 & 4.81 & $\mathrm{H}(\mathrm{N})$ & 5.80 & 0.30 & $6.10 \pm 0.31$ \\
\hline 9 & 8.43 & -0.16 & 8.27 & 7.86 & H7 & 2.97 & -0.06 & 2.91 & 2.91 & $\mathrm{H}\left(\mathrm{N}^{\prime}\right)$ & 5.79 & 0.50 & $6.29 \pm 0.31$ \\
\hline 11 & 2.60 & -0.20 & 2.40 & 2.40 & $\mathrm{H} 8 / 9 \mathrm{a}$ & 1.92 & -0.05 & 1.87 & 1.77 & $\mathrm{H} 7 \mathrm{a}$ & 4.18 & -0.02 & $4.16 \pm 0.21$ \\
\hline 12 & 2.57 & -0.13 & 2.44 & 2.36 & $\mathrm{H} 8 / 9 \mathrm{~b}$ & 1.18 & -0.05 & 1.13 & 1.09 & $\mathrm{H} 7 \mathrm{~b}$ & 4.63 & -0.21 & $4.42 \pm 0.22$ \\
\hline 13 & 0.91 & -0.01 & 0.90 & 0.48 & $\mathrm{H} 12 \mathrm{a}$ & 0.68 & 0.25 & 0.93 & 0.71 & $\mathrm{H} 8 \mathrm{a}$ & 4.41 & -0.25 & $4.16 \pm 0.21$ \\
\hline 14 & 0.77 & 0.01 & 0.78 & 0.48 & $\mathrm{H} 12 \mathrm{~b}$ & 1.30 & 0.09 & 1.39 & 0.98 & $\mathrm{H} 8 \mathrm{~b}$ & 4.26 & -0.24 & $4.02 \pm 0.20$ \\
\hline 15 & 0.95 & -0.01 & 0.94 & 0.48 & - & - & - & - & - & - & - & - & - \\
\hline $\mathrm{ADD}^{\mathrm{f}}$ & 0.40 & - & 0.27 & - & - & 0.11 & - & 0.13 & - & - & - & - & - \\
\hline
\end{tabular}


${ }^{\text {a }} \delta^{\text {gas }}$ refers to the four-component gas-phase calculations.

${ }^{\mathrm{b}} \Delta \delta^{\text {solv. }}$ is the approximate (sum of direct and indirect) solvent corrections obtained from the gasphase and solvent $\left(\mathrm{CHCl}_{3}\right)$ calculations using SO-ZORA.

${ }^{\mathrm{c}} \delta^{\text {tot. }}$ is the total chemical shift including solvent effects.

d This work.

${ }^{\mathrm{e}}$ In complex 2, H8a and H9a are in the same chemical environment and both point in the direction of C12. This is also true for $\mathrm{H} 8 \mathrm{~b}$ and $\mathrm{H} 9 \mathrm{~b}$, but they both point toward $\mathrm{C} 6$ and $\mathrm{C} 11$. H12a points in the opposite direction of the tungsten, whereas $\mathrm{H} 12 \mathrm{~b}$ points towards tungsten.

${ }^{\mathrm{f}}$ Mean absolute deviation (MAD), calculated with respect to the experimental values.

The ${ }^{13} \mathrm{C}$ chemical shifts of $\mathbf{1}-\mathbf{3}$ are listed in Table 3. The results for $\mathbf{1}$ show that the two carbon atoms attached to the phosphorus atom are highly deshielded compared to the carbon atoms in the six-membered ring. Of these two, C10 (bonded to both phosphorus and tin) is deshielded by $11 \mathrm{ppm}$ compared to C6 (bonded to phosphorus and C7). The largest deviation between experimental and calculated ${ }^{13} \mathrm{C}$ chemical shifts of $19.5 \mathrm{ppm}$ was found for $\mathrm{C} 10$. In order to estimate the influence of tungsten pentacarbonyl on the chemical shifts of the carbon atoms nearby, a comparison with the corresponding uncomplexed 2-trimethylstannyl-4,5dimethylphosphinine has been made. The experimental chemical shift of C6 in $\mathbf{1}$ differs from that of the uncomplexed compound by 2.4 ppm, whereas the chemical shift of C10 differs by 5.1 ppm (the calculated values confirm this observation showing differences of 2.9 ppm and 5.7 ppm, respectively). The calculated chemical shift for $\mathrm{C} 10$ of the uncomplexed compound deviated from experiment by $20.1 \mathrm{ppm}$, showing similar disagreement as in 1 (19.5 ppm). Adding one explicit solvent molecule $\left(\mathrm{CHCl}_{3}\right)$ in the $\mathrm{C} 10$ region as well as in the outside region of the trimethylstannyl group of $\mathbf{1}$, improves the C10 chemical shift by approximately $1 \%$. We also calculated the $\mathrm{C} 10$ chemical shift by elongating and shortening the Sn-C10 bond length. Shortening the Sn-C10 bond by $0.1 \AA$ improves the chemical shift by $3.2 \mathrm{ppm}$ (180.1 ppm). In contrast, when the bond was elongated by $0.1 \AA$, the chemical shift became worse by $5.6 \mathrm{ppm}$ (188.9 ppm). Further studies (see section 4.3, vide infra) indicate that calculations have difficulties to describe this region well. We speculate that the discrepancy either relates to the treatment of atoms close to tin and/or phosphorous or vibrational corrections. The experimental chemical shift of $\mathrm{C} 8$ in $\mathbf{1}$ has also a difference of $1.3 \mathrm{ppm}$ from the corresponding carbon 
chemical shift of the uncomplexed 2-trimethylstannyl-4,5-dimethylphosphinine, ${ }^{[50]}$ whereas the calculated values show a difference of $2.0 \mathrm{ppm}$.

The $\mathrm{sp}^{3}$-hybridized carbon atoms attached to tin are highly shielded compared to standard $\mathrm{sp}^{3}$ carbon atom chemical shifts. Among these carbon atoms, the atom furthest away from the carbonyls is shielded by about $11.7 \mathrm{ppm}$ (see Table 3). On the other hand, the methyl carbon atoms attached to the phosphinine ring are deshielded compared to the methyl carbon atoms attached to tin, and resonate in the same region as those of the ring methyl carbon atoms of the uncomplexed 2-trimethylstannyl-4,5-dimethylphosphinine (23.53 ppm for C11 and $22.27 \mathrm{ppm}$ for $\mathrm{C} 12$ of the free ligand). ${ }^{[50]}$ The chemical shifts of the carbonyl carbon atoms of $\mathbf{1}$ are deshielded compared to carbon atoms of tungsten hexacarbonyl $(192.0 \mathrm{ppm})^{[51]}$ because of the electron-withdrawing effect of the sixth ligand. The solvent calculations suggest that C9 is more sensitive than the other carbon atoms to the choice of solvent and that $\mathrm{C} 10$ is the least sensitive. It may be speculated that a steric influence of the trimethyltin group prevents the solvent from accessing $\mathrm{C} 10$. In general, the calculated solvent-corrected chemical shifts of the carbon atoms of the ring are in fair agreement with experiment.

There are three kinds of norbornene carbon atoms in $\mathbf{2}$. Of these, those attached to tungsten (C6 and C11) are highly deshielded, by $47 \mathrm{ppm}$ experimentally and by $35 \mathrm{ppm}$ in the calculations, compared to the corresponding carbon chemical shifts of uncomplexed norbornene (135.5 ppm) ${ }^{[49]}$ Such an effect is mainly due to the four horizontal carbonyl groups, which cause further deshielding of the carbon atoms of the sixth ligand. C12 is shifted slightly downfield by about $5 \mathrm{ppm}$ compared to $\mathrm{C} 7$ and $\mathrm{C} 10$ of the norbornene ligand of $\mathbf{2}$ in the experimental and calculated values (see Table 3). However, C7 has a comparable chemical shift (42.6 ppm) to the corresponding carbon atom of the uncomplexed norbornene (42.4 ppm) ${ }^{[49]}$ As also observed for the proton chemical shifts, the inclusion of solvent effects improves the agreement between the calculated and the experimental ${ }^{13} \mathrm{C}$ values of $\mathbf{2}$ considerably. In $\mathbf{3}$, the carbon atom bonded to sulfur (C6) has a calculated chemical shift of $185.6 \mathrm{ppm}$, which is larger compared to the other carbon atoms of the ring (being $49.2 \mathrm{ppm}$ for C7 and C8). As highlighted in the Molecular Geometries section, the carbonyl group oriented trans to the sixth ligand in all the complexes has a shorter bond length than the others, leading to $\mathrm{C} 3$ having larger chemical shift in all the three complexes than the other carbonyl carbon atoms (Table 3). The experimental ${ }^{13} \mathrm{C}$ chemical shifts 
of the carbonyl carbons are also in fair agreement with previous literature data, ranging from 196 ppm to 201 ppm, a characteristic signal for $\mathrm{W}(\mathrm{CO})_{5} \mathrm{~L}$ complexes $\left(\mathrm{L}=\right.$ sixth ligand). ${ }^{[52]}$ However, unlike in 2 , the calculated $\delta\left({ }^{13} \mathrm{CO}\right)$ values for $\mathrm{C} 4$ and $\mathrm{C} 5$ in $\mathbf{1}$ show large deviations from the corresponding experimental values.

The calculated chemical shift of phosphorus $\left({ }^{31} \mathrm{P}\right)$ in $\mathbf{1}(178.5 \mathrm{ppm})$ is in good agreement with the experimental result, $174.7 \mathrm{ppm}$. This experimental $\delta\left({ }^{31} \mathrm{P}\right)$ of the newly synthesized complex is less than the corresponding ${ }^{31} \mathrm{P}$ chemical shift of the uncomplexed 2trimethylstannyl-4,5-dimethylphosphinine by $42.26 \mathrm{ppm}$, which has an experimental value of 216.16 ppm. $^{[50]}$ The observed decrease of the chemical shift upon coordination can be rationalized by the trans influence of the carbonyl ligand, making the phosphorus atom shielded compared to the free ligand. The measured chemical shift for ${ }^{119} \mathrm{Sn}$ in $\mathbf{1}$ is $-1.44 \mathrm{ppm}$, whereas the solvent and relativistically corrected value obtained from the calculations is $-2.13 \mathrm{ppm}$.

Table 3. Experimental and calculated (BP86) ${ }^{13} \mathrm{C},{ }^{31} \mathrm{P}$ and ${ }^{119} \mathrm{Sn}$ chemical shifts for complexes 1 $-\mathbf{3}$ (in ppm).

\begin{tabular}{|c|c|c|c|c|c|c|c|c|c|c|c|}
\hline & \multicolumn{4}{|c|}{1} & \multicolumn{4}{|c|}{2} & \multicolumn{3}{|c|}{3} \\
\hline & $\delta^{\mathrm{gas}, \mathrm{a}}$ & $\Delta \delta^{\text {solv.b }}$ & $\delta^{\text {tot.c }}$ & $\delta^{\text {exp.,d }}$ & $\delta^{\text {gas, a }}$ & $\Delta \delta^{\text {solv. b }}$ & $\delta^{\text {tot., c }}$ & $\delta^{\text {exp. }[28]}$ & $\delta^{\mathrm{gas}, \mathrm{a}}$ & $\Delta \delta^{\text {solv. b }}$ & $\delta^{\text {tot., c }}$ \\
\hline $\mathrm{C} 1^{\mathrm{e}, \mathrm{f}}$ & 209.8 & -3.7 & 206.1 & 195.8 & 199.8 & -4.3 & 195.5 & 197.5 & 208.3 & -4.6 & $203.7 \pm 5.1$ \\
\hline $\mathrm{C} 2^{\mathrm{f}}$ & 209.8 & -3.7 & 206.1 & 195.8 & 199.8 & -4.3 & 195.5 & 197.5 & 208.3 & -4.6 & $203.7 \pm 5.1$ \\
\hline C3 & 213.5 & -4.3 & 209.2 & 198.9 & 202.7 & -4.6 & 198.1 & 200.6 & 213.5 & -5.5 & $208.0 \pm 5.2$ \\
\hline $\mathrm{C} 4^{\mathrm{f}}$ & 209.8 & -3.7 & 206.1 & 195.8 & 199.8 & -4.3 & 195.5 & 197.5 & 208.3 & -4.6 & $203.7 \pm 5.1$ \\
\hline $\mathrm{C} 5^{\mathrm{f}}$ & 209.8 & -3.7 & 206.1 & 195.8 & 199.8 & -4.3 & 195.5 & 197.5 & 208.3 & -4.6 & $203.7 \pm 5.1$ \\
\hline C6 & 167.7 & -4.7 & 163.0 & 153.7 & 94.2 & -12.2 & 82.0 & 88.6 & 190.8 & -5.2 & $185.6 \pm 4.5$ \\
\hline C7 & 157.5 & -5.2 & 152.3 & 147.6 & 52.4 & -13.5 & 38.9 & 42.6 & 52.3 & -3.1 & $49.2 \pm 2.5$ \\
\hline $\mathrm{C} 8$ & 146.6 & -8.6 & 138.0 & 136.0 & 33.2 & -7.1 & 26.1 & 26.5 & 53.4 & -3.8 & $49.2 \pm 2.5$ \\
\hline C9 & 156.0 & -9.3 & 146.7 & 146.8 & 33.1 & -7.1 & 26.0 & 26.5 & - & - & - \\
\hline $\mathrm{C} 10$ & 185.1 & -1.8 & 183.3 & 163.8 & 52.4 & -13.5 & 38.9 & 42.6 & - & - & - \\
\hline C11 & 29.3 & -4.9 & 24.4 & 23.5 & 94.1 & -12.4 & 81.7 & 88.6 & - & - & - \\
\hline $\mathrm{C} 12$ & 28.2 & -2.5 & 25.7 & 22.3 & 41.0 & -6.9 & 34.1 & 37.6 & - & - & - \\
\hline C13 & 0.3 & -6.2 & -5.9 & -6.7 & - & - & - & - & - & - & - \\
\hline
\end{tabular}




\begin{tabular}{|l|r|r|r|r|r|r|r|r|r|r|c|}
\hline C14 & -3.3 & -3.1 & -6.4 & -6.7 & - & - & - & - & - & - & - \\
\hline C15 & 0.4 & -6.2 & -5.8 & -6.7 & - & - & - & - & - & - & - \\
\hline P & 182.8 & -4.3 & 178.5 & 174.7 & - & - & - & - & - & - & - \\
\hline Sn & -9.23 & 7.1 & -2.13 & -1.44 & - & - & - & - & - & - & - \\
\hline MAD $^{\mathrm{g}}$ & 10.63 & - & 5.76 & - & 4.89 & - & 2.98 & - & - & - & - \\
\hline
\end{tabular}

${ }^{\mathrm{a}} \delta^{\text {gas }}$ refers to the four-component gas-phase calculations.

${ }^{\mathrm{b}} \Delta \delta^{\text {solv. }}$ is the approximate (sum of direct and indirect) solvent corrections obtained from the gas-phase and solvent $\left(\mathrm{CHCl}_{3}\right)$ calculations using SO-ZORA.

${ }^{\mathrm{c}} \delta^{\text {tot. }}$ is the total chemical shift including solvent effects.

${ }^{\mathrm{d}}$ This work.

${ }^{\mathrm{e}} \mathrm{W}(\mathrm{CO})_{6}: \delta\left({ }^{13} \mathrm{C}\right)_{\text {exp. }}=192.0 \mathrm{ppm},{ }^{[51]}$ and solvent effect corrected $\delta\left({ }^{13} \mathrm{C}\right)_{\mathrm{DKS}}$ is $196.8 \mathrm{ppm}$

${ }^{\mathrm{f}}$ Average chemical shifts for all the horizontal carbonyl carbons are reported.

${ }^{\mathrm{g}}$ Mean absolute deviation (MAD), calculated with respect to the experimental values.

\subsection{NMR Spin-Spin Coupling Constants}

Calculated and experimental spin-spin coupling constants for $\mathbf{1}$ are listed in Table 4. The experimental results (with the exception of ${ }^{1} J\left({ }^{31} \mathrm{P}_{-}{ }^{13} \mathrm{C} 6\right),{ }^{1} J\left({ }^{31} \mathrm{P}_{-}{ }^{13} \mathrm{C} 10\right),{ }^{1} J\left({ }^{119} \mathrm{Sn}-{ }^{13} \mathrm{C} 10\right)$ and $\left.{ }^{1} J\left({ }^{119} \mathrm{Sn}-{ }^{13} \mathrm{CH}_{3}\right)\right)$ are reproduced satisfactorily by the calculations including solvent effects (although the solvent effects are rather small compared to the effects on the chemical shifts, as is generally the case ${ }^{[53-54]}$ ).

A comparison of the experimentally determined relative signs of the coupling constants with the signs calculated using the four-component Dirac-Kohn-Sham (DKS) and the two-component SO-ZORA (see Table S1 for the latter) revealed an unexpected inconsistency. The sign of the ${ }^{1} J\left({ }^{31} \mathrm{P}_{-}{ }^{13} \mathrm{C} 6\right)$ is not reproduced correctly. The experimentally determined relationships of this coupling to the other couplings of the phosphorous atom predict a positive coupling constant, while the calculated coupling constant is negative. Both the calculated ${ }^{1} J\left({ }^{31} \mathrm{P}_{-}{ }^{13} \mathrm{C} 6\right)$ and ${ }^{1} J\left({ }^{31} \mathrm{P}-\right.$ ${ }^{13} \mathrm{C} 10$ ) couplings and the $\mathrm{C} 6$ and $\mathrm{C} 10$ chemical shifts were among the calculated results with the largest deviation from experiment. It is unclear what causes the difficulties in reproducing this region correctly. However, a decrease in the W-P bond length by $0.1 \AA$ results in an improvement of the ${ }^{1} J\left({ }^{31} \mathrm{P}_{-}{ }^{13} \mathrm{C} 6\right)$ coupling from -17.1 to $-5.1 \mathrm{~Hz}$ and the ${ }^{1} J\left({ }^{31} \mathrm{P}_{-}{ }^{13} \mathrm{C} 10\right)$ coupling 
from -62.5 to $-49.5 \mathrm{~Hz}$ using B3LYP (see Table 4 and Table S1), suggesting that vibrational corrections may be responsible for the discrepancy.

Of all the coupling constants, ${ }^{1} J\left({ }^{119} \mathrm{Sn}-{ }^{13} \mathrm{C} 10\right)$ and ${ }^{2} J\left({ }^{119} \mathrm{Sn}-{ }^{31} \mathrm{P}\right)$ show the strongest solvent dependence. The experimental ${ }^{1} J\left({ }^{13} \mathrm{C}-{ }^{183} \mathrm{~W}\right)$ for the cis carbonyls is $125 \mathrm{~Hz}$, which is comparable to the ${ }^{1} J\left({ }^{13} \mathrm{C}-{ }^{183} \mathrm{~W}\right)$ value for $\mathrm{W}(\mathrm{CO})_{6}$ of $126 \mathrm{~Hz} \cdot{ }^{[55-56]}$ However, the value for the trans carbonyl is larger $(147.4 \mathrm{~Hz})$, indicating a strong trans influence of the carbonyl on the sixth ligand. Similar trends of trans influence are also observed for the other two complexes based on the differences between the calculated and the experimental ${ }^{1} J\left({ }^{13} \mathrm{C}-{ }^{183} \mathrm{~W}\right)$ values involving the carbonyls (see Table 4 and its footnotes). 
Table 4. Selected experimental and calculated spin-spin coupling constants (in $\mathrm{Hz}$ ) of $\mathbf{1}$. The signs of the experimental values are given in brackets when the relative sign pattern corresponds to the relative pattern of the calculated values.

\begin{tabular}{|c|c|c|c|c|c|c|c|}
\hline \multirow[t]{2}{*}{ Coupling constants } & \multicolumn{3}{|c|}{ BP86 } & \multicolumn{3}{|c|}{ B3LYP } & \multirow[t]{2}{*}{$J^{\text {exp., d }}$} \\
\hline & $J^{\text {gas, a }}$ & $\Delta J^{\text {solv., b }}$ & $J^{\text {tot., c }}$ & $J^{\mathrm{gas}, \mathrm{a}}$ & $\Delta J^{\text {solv., b }}$ & $J^{\text {tot., c }}$ & \\
\hline${ }^{1} J\left({ }^{119} \mathrm{Sn}^{13} \mathrm{C} 10\right)$ & -130.6 & -7.4 & -138.0 & -240.0 & -5.1 & -245.1 & $(-) 340.6$ \\
\hline${ }^{1} J\left({ }^{119} \mathrm{Sn}^{13} \mathrm{CH}_{3}\right){ }^{\mathrm{e}}$ & -141.4 & -5.4 & -146.8 & -275.2 & -4.0 & -279.2 & $(-) 360.7$ \\
\hline${ }^{1} J\left({ }^{183} \mathrm{~W}^{13} \mathrm{C}(\text { cis }-\mathrm{CO})\right)^{\mathrm{e}, \mathrm{f}}$ & 128.4 & 0.5 & 128.9 & 130.7 & 0.2 & 130.9 & 125.9 \\
\hline${ }^{1} J\left({ }^{183} \mathrm{~W}^{13} \mathrm{C}(\right.$ trans $-\mathrm{CO}){ }^{\mathrm{f}}$ & 164.6 & -0.7 & 163.9 & 170.6 & -0.8 & 169.8 & 147.4 \\
\hline${ }^{1} J\left({ }^{31} \mathrm{P}^{183} \mathrm{~W}\right)$ & 222.3 & 1.7 & 224.0 & 248.6 & 1.6 & 250.2 & 259.6 \\
\hline${ }^{1} J\left({ }^{31} \mathrm{P}^{13} \mathrm{C} 6\right)$ & -38.5 & -0.2 & -38.7 & -17.0 & -0.1 & -17.1 & 9.5 \\
\hline${ }^{1} J\left({ }^{31} \mathrm{P}^{13} \mathrm{C} 10\right)$ & -86.1 & 0.5 & -85.6 & -62.9 & 0.4 & -62.5 & 26.9 \\
\hline${ }^{2} J\left({ }^{183} \mathrm{~W}^{13} \mathrm{C} 10\right)$ & 6.4 & 0.2 & 6.6 & 7.0 & 0.1 & 7.1 & 6.9 \\
\hline${ }^{2} J\left({ }^{31} \mathrm{P}^{1} \mathrm{H} 6\right)$ & 32.7 & 0.7 & 33.4 & 32.4 & 0.5 & 32.9 & 23.3 \\
\hline${ }^{2} J\left({ }^{31} \mathrm{P}^{13} \mathrm{C} 9\right)$ & -14.4 & 0.1 & -14.3 & -21.4 & 0.1 & -21.3 & $(-) 21.1$ \\
\hline${ }^{2} J\left({ }^{119} \mathrm{Sn}^{13} \mathrm{C} 9\right)$ & -29.5 & 3.5 & -26.0 & -24.0 & 2.6 & -21.4 & $(-) 10.9$ \\
\hline${ }^{2} J\left({ }^{31} \mathrm{P}^{13} \mathrm{C}(\text { cis- } \mathrm{CO})\right)^{\mathrm{e}}$ & -5.9 & 0.3 & -5.6 & -5.9 & -0.2 & -6.1 & $(-) 9.3$ \\
\hline${ }^{2} J\left({ }^{31} \mathrm{P}^{13} \mathrm{C}(\right.$ trans $-\mathrm{CO})$ & 38.4 & -0.9 & 37.5 & 34.9 & -0.6 & 34.3 & 28.0 \\
\hline${ }^{2} J\left({ }^{31} \mathrm{P}^{119} \mathrm{Sn}\right)$ & -219.3 & 8.3 & -211.0 & -197.2 & 6.7 & -190.5 & $(-) 193.7$ \\
\hline${ }^{3} J\left({ }^{31} \mathrm{P}^{13} C \mathrm{H} 3\right)^{\mathrm{e}}$ & 3.0 & 0.5 & 3.5 & 2.6 & 0.1 & 2.7 & 2.5 \\
\hline${ }^{3} J\left({ }^{31} \mathrm{P}^{1} \mathrm{H} 9\right)$ & 33.9 & 1.1 & 35.0 & 32.9 & 0.2 & 33.1 & 30.7 \\
\hline${ }^{3} J\left({ }^{119} \mathrm{Sn}^{1} \mathrm{H} 9\right)$ & -72.9 & -0.7 & -73.6 & -71.7 & -0.7 & -72.4 & $(-) 61.4$ \\
\hline${ }^{4} J\left({ }^{119} \mathrm{Sn}^{1} \mathrm{H} 6\right)$ & -25.5 & -0.3 & -25.8 & -22.5 & -0.3 & -22.8 & $(-) 20.1$ \\
\hline $\mathrm{MAD}^{\mathrm{g}}$ & 41.3 & - & 39.9 & 21.8 & - & 21.1 & - \\
\hline
\end{tabular}

${ }^{\mathrm{a}} J^{\mathrm{gas}}$ refers to the four-component gas-phase calculations.

${ }^{\mathrm{b}} \Delta J^{\text {solv. }}$ is the approximate (sum of direct and indirect) solvent correction obtained from the gas-

phase and solvent (in $\mathrm{CHCl}_{3}$ ) calculations using SO-ZORA.

${ }^{\mathrm{c}} J^{\text {tot. }}$ is the total spin-spin coupling constant including direct and indirect solvent effects.

${ }^{\mathrm{d}}$ This work.

${ }^{\mathrm{e}}$ Average spin-spin coupling constants were reported.

${ }^{\mathrm{f}}{ }^{1} \mathrm{~J}\left({ }^{13} \mathrm{C}-{ }^{183} \mathrm{~W}\right)_{\text {exp. }}$ for $\mathrm{W}(\mathrm{CO})_{6}$ is $126 \mathrm{~Hz}^{[55-56]}$ and our BP86 calculated value is $126.5 \mathrm{~Hz}$;

${ }^{1} J\left({ }^{13} \mathrm{C}(\right.$ cis-CO $\left.)-{ }^{183} \mathrm{~W}\right)$ exp. for 2 is $126 \mathrm{~Hz}^{[28]}$ and our BP86 calculated value is $124.9 \mathrm{~Hz}$; whereas

${ }^{1} J\left({ }^{13} \mathrm{C}(\text { trans }-\mathrm{CO})-{ }^{183} \mathrm{~W}\right)_{\text {exp. }}$ for 2 is $155 \mathrm{~Hz}^{[28]}$ and our BP86 calculated value is $155.3 \mathrm{~Hz}$.

${ }^{g}$ Mean absolute deviation (MAD), calculated with respect to the experimental values. 

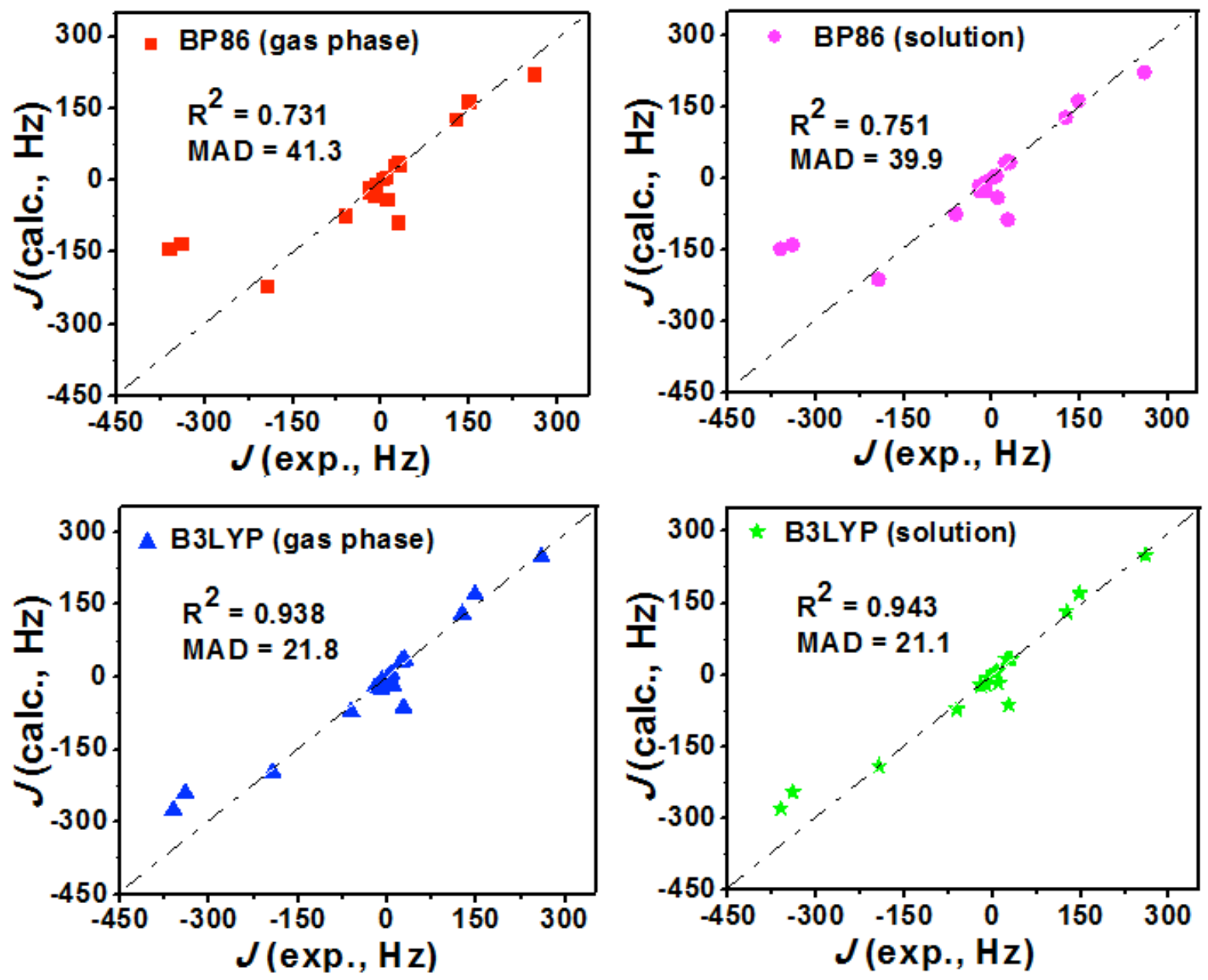

Figure 2. Correlation diagrams between the four-component relativistically calculated (BP86 and B3LYP) and experimental spin-spin coupling constants of 1, all listed in Table 4. Mean absolute deviation (MAD) is calculated with respect to the experimental values. Plotted using OriginPro 8, OriginLab.

The effect of the choice of exchange-correlation functional on the spin-spin coupling constants can be illustrated by comparing results obtained with BP86 and B3LYP. ${ }^{2} J\left({ }^{119} \mathrm{Sn}-{ }^{31} \mathrm{P}\right)$ obtained from BP86 is $-211.0 \mathrm{~Hz}$, whereas B3LYP gives $-190.5 \mathrm{~Hz}$, which is close to the experimental value of $-193.7 \mathrm{~Hz}$. The B3LYP calculated value for ${ }^{1} J\left({ }^{31} \mathrm{P}_{-}{ }^{183} \mathrm{~W}\right)$ is $250.2 \mathrm{~Hz}$, also in better agreement with the experimental value $(259.6 \mathrm{~Hz})$ compared to that of the BP86, being 224.0 Hz. Another result demonstrating the sensitivity of the spin-spin coupling constant on the choice of exchange-correlation functional is that of ${ }^{1} J\left({ }^{119} \mathrm{Sn}^{-13} \mathrm{CH}_{3}\right)$. The experimental value for this 
coupling constant is $-360.6 \mathrm{~Hz}$, whereas BP86 gives $-146.8 \mathrm{~Hz}, 59 \%$ off from the experimental value while B3LYP gives $-276.2 \mathrm{~Hz}, 36 \%$ improvement over BP86 (see Table 4). In general, in contrast to BP86, B3LYP reproduces the experimental spin-spin coupling constants well, see Figure 2 showing that the $\mathrm{R}^{2}$ value is changing from 0.751 using BP86 to 0.943 using B3LYP in solution.

\section{CONCLUSIONS}

We have presented an analysis of the structural and NMR parameters of a newly synthesized tungsten carbonyl complex together with two additional tungsten complexes with different ligands. The optimized geometries show that the complexes have a pseudo-octahedral molecular geometry. The chemical shifts calculated for the three tungsten-carbonyl complexes using the four-component relativistic Hamiltonian are in good agreement with available experimental data. This work extends our previous study of the chemical shifts of proton and

carbon atoms for biologically relevant halogenated organic compounds, ${ }^{[15,22]}$ and shows the maturity of the four-component methods implemented in the ReSpect ${ }^{[21]}$ quantum chemical package in reproducing reliable chemical shifts and spin-spin coupling constants for chemically relevant molecular systems in a reasonable amount of time. For instance, the chemical shift calculation of compound $\mathbf{1}$, which has 40 atoms, took an overall computational time of not more than 30 hours on 3 nodes each having 16 processors (Intel E5-2670, 2.6 GHz). Moreover, with the help of the four-component relativistic NMR property calculations, we confidently assigned the measured experimental values for the newly synthesized organometallic complex. In addition, we have presented benchmark quality data for all the complexes studied. The study also showed the importance of including both relativistic and solvent effects in the analysis of organometallic complexes in order to obtain reasonable agreement between experimental data and calculated values for the chemical shifts and spin-spin coupling constants. B3LYP gives spin-spin coupling constants that are in much better agreement with the experimental values compared to BP86, the effect being most pronounced for the coupling constants involving tin.

\section{Acknowledgments}


This work has received support from the Research Council of Norway through a Centre of Excellence Grant (Grant No. 179568/V30) and project grants (Grant No. 214095, 177558) and the European Research Council starting grant, (Grant No. 279619). The work has also received support from the Norwegian Supercomputing program NOTUR (Grant No. NN4654K).

\section{REFERENCES}

[1] M. Zhou, L. Andrews, C. W. Bauschlicher, Chem. Rev. 2001, 101, 1931-1962.

[2] J. R. Katzer, R. Sivasubramanian, Catal. Rev. 1979, 20, 155-208.

[3] A. Andreini, J. C. Mol, J. Chem. Soc., Farad. Trans. 1: Phys. Chem. Cond. Phases 1985, $81,1705-1714$.

[4] F. Verpoort, A. R. Bossuyt, L. Verdonck, B. Coussens, J. Mol. Catalysis A: Chem. 1997, $115,207-218$.

[5] M. Nooraeipour, M. Moghadam, S. Tangestaninejad, V. Mirkhani, I. MohammadpoorBaltork, N. Iravani, J. Coord. Chem. 2011, 65, 226-238.

[6] S. D. Kohler, J. G. Ekerdt, J. Phys. Chem. 1994, 98, 1276-1281.

[7] D. G. Musaev, S. Irle, M. C. Lin, J. Phys. Chem. A 2007, 111, 6665-6673.

[8] H. Tan, M. Liao, D. Dai, K. Balasubramanian, J. Phys. Chem. A 1998, 102, 6801-6806.

[9] P. Pyykkö, A. Görling, N. Rösch, Mol. Phys. 1987, 61, 195-205.

[10] M. Kaupp, O. L. Malkina, V. G. Malkin, P. Pyykkö, Chem. Eur. J. 1998, 4, 118-126.

[11] J. Autschbach, Coord. Chem. Rev. 2007, 251, 1796-1821.

[12] J. Autschbach, S. Zheng, in Annual Reports on NMR Spectroscopy, Vol. Volume 67 (Ed.:

A. W. Graham), Academic Press, 2009, pp. 1-95.

[13] J. Autschbach, T. Ziegler, J. Chem. Phys. 2000, 113, 9410-9418.

[14] J. Autschbach, T. Ziegler, J. Am. Chem. Soc. 2001, 123, 3341-3349.

[15] K. O. Hanssen, B. Schuler, A. J. Williams, T. B. Demissie, E. Hansen, J. H. Andersen, J. Svenson, K. Blinov, M. Repisky, F. Mohn, G. Meyer, J. S. Svendsen, K. Ruud, M. Elyashberg, L. Gross, M. Jaspars, J. Isaksson, Angew. Chem. Int. Ed. 2012, 51, 1223812241.

[16] P. Hrobárik, V. Hrobáriková, A. H. Greif, M. Kaupp, Angew. Chem. Int. Ed. 2012, 51, 10884-10888. 
[17] P. Hrobárik, V. Hrobáriková, F. Meier, M. Repiský, S. Komorovský, M. Kaupp, J. Phys. Chem. A 2011, 115, 5654-5659.

[18] P. Manninen, P. Lantto, J. Vaara, K. Ruud, J. Chem. Phys. 2003, 119, 2623-2637.

[19] J. Vícha, C. Foroutan-Nejad, T. Pawlak, M. L. Munzarová, M. Straka, R. Marek, J. Chem. Theory Comput. 2015, 11, 1509-1517.

[20] E. v. Lenthe, J. G. Snijders, E. J. Baerends, J. Chem. Phys. 1996, 105, 6505-6516.

[21] ReSpect, version 3.4 .0 (2014); Relativistic Spectroscopy DFT program of authors S. Komorovsky, M. Repisky, V. G. Malkin, O. L. Malkina, M. Kaupp, K. Ruud, with contributions from R. Bast, U. Ekstrom, M. Kadek, S. Knecht, L. Konecny, E. Malkin., I. M. Ondik, (http://rel-qchem.sav.sk).

[22] T. B. Demissie, M. Repisky, S. Komorovsky, J. Isaksson, J. S. Svendsen, H. Dodziuk, K. Ruud, J. Phys. Org. Chem. 2013, 26, 679-687.

[23] S. Komorovsky, M. Repisky, K. Ruud, O. L. Malkina, V. G. Malkin, J. Phys. Chem. A 2013, 117, 14209-14219.

[24] T. B. Demissie, M. Repisky, H. Liu, K. Ruud, P. M. Kozlowski, J. Chem. Theory Comput. 2014, 10, 2125-2136.

[25] M. Repiský, S. Komorovský, O. L. Malkina, V. G. Malkin, Chem. Phys. 2009, 356, 236242.

[26] S. Komorovsky, M. Repisky, O. L. Malkina, V. G. Malkin, I. M. Ondik, M. Kaupp, J. Chem. Phys. 2008, 128, 104101.

[27] S. Komorovsky, M. Repisky, O. L. Malkina, V. G. Malkin, J. Chem. Phys. 2010, 132, 154101.

[28] M. Górski, A. Kochel, T. Szymańska-Buzar, Organometallics 2004, 23, 3037-3046.

[29] S. Merniz, M. Mokhtari, H. Mousser, L. Ouahab, A. Mousser, Acta Cryst. Sec. E 2010, 66, m629-m630.

[30] P. L. Floch, D. Carmichael, F. Mathey, in Synthetic Methods of Organometallic and Inorganic Chemistry, Vol. 3 (Ed.: W. A. Herrman), Georg Thieme Verlag, Stuttgart, 1996, pp. 167-171.

[31] A. D. Becke, Phys. Rev. A 1988, 38, 3098-3100.

[32] J. P. Perdew, Phys. Rev. B 1986, 33, 8822-8824. 
[33] A. D. Becke, J. Chem. Phys. 1993, 98, 5648-5652.

[34] C. Lee, W. Yang, R. G. Parr, Phys. Rev. B 1988, 37, 785-789.

[35] S. H. Vosko, L. Wilk, M. Nusair, Can. J. Phys. 1980, 58, 1200-1211.

[36] P. J. Stephens, F. J. Devlin, C. F. Chabalowski, M. J. Frisch, J. Phys. Chem. 1994, 98, $11623-11627$.

[37] E. v. Lenthe, E. J. Baerends, J. Comp. Chem. 2003, 24, 1142-1156.

[38] ADF2014, SCM, Theoretical Chemistry, E. J. Baerends, J. Autschbach, A. Berces, F. M. Bickelhaupt, C. Bo, P. M. Boerrigter, L. Cavallo, D. P. Chong, L. Deng, R. M. Dickson, D. E. Ellis, M. van Faassen, L. Fischer, T. H. Fan, C. Fonseca Guerra, S. J. A. van Gisbergen, J. A. Groeneveld, O. V. Gritsenko, M. Gruning, F. E. Harris, P. van den Hoek, C. R. Jacob, H. Jacobsen, L. Jensen, G. van Kessel, F. Kootstra, E. van Lenthe, D. A. McCormack, A. Michalak, J. Neugebauer, V. P. Osinga, S. Patchkovskii, P. H. T. Philipsen, D. Post, C. C. Pye, W. Ravenek, P. Ros, P. R. T. Schipper, G. Schreckenbach, J. G. Snijders, M. Sola, M. Swart, D. Swerhone, G. teVelde, P. Vernooijs, L. Versluis, L. Visscher, O. Visser, F. Wang, T. A. Wesolowski, E. van Wezenbeek, G. Wiesenekker, S. Wolff, T. Woo, A. Yakovlev, T. Ziegler, Vrije Universiteit: Amsterdam, The Netherlands (http://www.scm.com/), 2014.

[39] E. v. Lenthe, E. J. Baerends, J. G. Snijders, J. Chem. Phys. 1993, 99, 4597-4610.

[40] E. v. Lenthe, A. E. Ehlers, E. J. Baerends, J. Chem. Phys. 1999, 110, 8943-8953.

[41] S. Grimme, Wiley Interdisciplinary Reviews: Comp. Mol. Sc. 2011, 1, 211-228.

[42] T. Helgaker, M. Watson, N. C. Handy, J. Chem. Phys. 2000, 113, 9402-9409.

[43] F. Jensen, J. Chem. Theory Comput. 2006, 2, 1360-1369.

[44] K. G. Dyall, Theor. Chem. Acc. 2002, 108, 335-340.

[45] K. G. Dyall, Theor. Chem. Acc. 2004, 112, 403-409.

[46] K. G. Dyall, A. S. P. Gomes, Theor. Chem. Acc. 2010, 125, 97-100.

[47] A. Klamt, G. Schuurmann, J. Chem. Soc., Perkin Trans. 2 1993, 799-805.

[48] G. M. Anstead, R. Srinivasan, C. S. Peterson, S. R. Wilson, J. A. Katzenellenbogen, J. Am. Chem. Soc. 1991, 113, 1378-1385.

[49] H. Gunther, NMR Spectroscopy: An Introduction, John Wiley and Sons, Ltd, Chichester, West Sussex, , 1980. 
[50] P. Le Floch, L. Ricard, F. Mathey, Bull. Soc. Chim. Fr. 1994, 131, 330-334.

[51] B. E. Mann, J. Chem. Soc., Dalton Trans. 1973, 2012-2015.

[52] L. Broeckaert, J. Turek, R. Olejník, A. Růžička, M. Biesemans, P. Geerlings, R. Willem, F. De Proft, Organometallics 2013, 32, 2121-2134.

[53] T. Helgaker, S. Coriani, P. Jørgensen, K. Kristensen, J. Olsen, K. Ruud, Chem. Rev. 2012, 112, 543-631.

[54] T. Helgaker, M. Jaszuński, K. Ruud, Chem. Rev. 1999, 99, 293-352.

[55] M. P. Guy, J. T. Guy, D. W. Bennett, Organometallics 1986, 5, 1696-1702.

[56] M. F. Guns, E. G. Claeys, G. P. Van Der Kelen, J. Mol. Struct. 1979, 53, 45-53. 